\title{
Barriers and Facilitators to Healthy Lifestyle Changes in Minority Ethnic Populations in the UK: a Narrative Review
}

\author{
Naina Patel ${ }^{1} \cdot$ Harriet Batista Ferrer $^{2} \cdot$ Freya $_{\text {Tyrer }}{ }^{3}\left(\mathbb{D} \cdot\right.$ Paula Wray $^{1} \cdot$ Azhar Farooqi $^{4}$. \\ Melanie J. Davies ${ }^{1} \cdot$ Kamlesh Khunti $^{1}$
}

Received: 25 May 2016 /Revised: 8 August 2016 / Accepted: 14 November 2016 /Published online: 7 December 2016

(C) The Author(s) 2016. This article is published with open access at Springerlink.com

\begin{abstract}
Minority ethnic populations experience a disproportionate burden of health inequalities compared with the rest of the population, including an increased risk of type 2 diabetes (T2DM). The purpose of this narrative review was to explore knowledge and attitudes around diabetes, physical activity and diet and identify barriers and facilitators to healthy lifestyle changes in minority ethnic populations in the UK. The narrative review focused on three key research topics in relation to barriers and facilitators to healthy lifestyle changes in minority adult ethnic populations: (i) knowledge and attitudes about diabetes risk; (ii) current behaviours and knowledge about physical activity and diet; and (iii) barriers and facilitators to living a healthier lifestyle. Nearly all of the studies that we identified reported on South Asian minority ethnic populations; we found very few studies on other minority ethnic populations. Among South Asian communities, there was generally a good understanding of diabetes and its associated risk factors. However, knowledge about the levels of physical activity required to gain health benefits was relatively poor and eating patterns varied. Barriers to healthy lifestyle changes identified included language barriers, prioritising work over physical activity to provide for the family, cultural barriers with regard to serving and eating traditional food, different perceptions of a healthy body weight and fear of
\end{abstract}

Freya Tyrer

fct2@le.ac.uk

1 Diabetes Research Centre, University of Leicester, Leicester, UK

2 School of Social and Community Medicine, University of Bristol, Bristol, UK

3 Department of Health Sciences, University of Leicester, Leicester, UK

4 Leicester City Clinical Commissioning Group, Leicester, UK racial harassment or abuse when exercising. Additional barriers for South Asian women included expectations to remain in the home, fear for personal safety, lack of same gender venues and concerns over the acceptability of wearing 'western' exercise clothing. Facilitators included concern that weight gain might compromise family/carer responsibilities, desire to be healthy, T2DM diagnosis and exercise classes held in 'safe' environments such as places of worship. Our findings suggest that South Asian communities are less likely to engage in physical activity than White populations and highlight the need for health promotion strategies to engage people in these communities. There is a gap in knowledge with regard to diabetes, physical activity, diet and barriers to healthy lifestyle changes among other ethnic minority populations in the UK; we recommend further research in this area.

Keywords Diabetes $\cdot$ Ethnic minority populations $\cdot$ South Asian $\cdot$ UK $\cdot$ Healthy lifestyle changes $\cdot$ Narrative review

\section{Background}

Minority ethnic populations experience a disproportionate burden of health inequalities in a number of disease areas compared with the rest of the population. These include an increased prevalence of type 2 diabetes mellitus (T2DM), reported to be up to six times higher among South Asian (Indian, Pakistani, Bangladeshi and Sri Lankan) communities [1-5] and up to three times higher among Black African and Black Caribbean communities [6] compared with White populations in the UK.

Increasing levels of obesity and sedentary lifestyles have been associated with a rise in T2DM [7, 8]. However, the relationship between obesity and ethnicity is not always clear. On the surface, it would appear that ethnic minority groups (at 
least men) have a lower risk of obesity compared with the White population. The 2004 Health Survey for England reported that the prevalence of obesity was lower among men from Black African, Indian, Pakistani, Bangladeshi and Chinese minority ethnic groups. In contrast, women from Black African, Black Caribbean and Pakistani communities (but not Chinese) had higher rates of obesity [9]. However, it is argued that, in South Asian communities, a substantially lower body mass index (BMI) and waist circumference are needed to confer equivalent risk factor profiles $[10,11]$ because a more centralised distribution of body fat is typically observed $[12,13]$. This has led to the World Health Organisation (WHO) recommending a lower BMI threshold for obesity $\left(27.5 \mathrm{~kg} / \mathrm{m}^{2}\right)$ for South Asian populations [14], and this threshold is lower still in the UK $\left(25.0 \mathrm{~kg} / \mathrm{m}^{2}\right)$ [15]. The new threshold would indicate higher rates of obesity among Indian, Bangladeshi men and women and higher rates of obesity among Pakistani women compared with White populations [16]. The Chinese population has also been identified as having higher blood pressure level at significantly lower BMI values compared with White Europeans [10, 17], but BMI thresholds are yet to be agreed.

Global and national guidance recognise the importance of the prevention of chronic diseases. The UK follows WHO guidance, which recommends limiting energy intake from total fats, replacing saturated fats with unsaturated fats, increasing intake of fruit and vegetables, whole grains and nuts and limiting simple sugars, salt and sodium [7, 18]. However, it is acknowledged that dietary habits vary within and between ethnic groups and are influenced by multiple factors, including food availability, financial resources, health, food and religious beliefs and cultural customs [19].

The importance of physical activity is also recognised in national and international guidance. For adults, at least $150 \mathrm{~min}$ of moderate intensity or $75 \mathrm{~min}$ of vigorous intensity physical activity each week is recommended [20-22]. Currently, recommendations do not differ by ethnic group but the influence of heritability on cardiovascular fitness is well established [23, 24]. There is increasing evidence of a relationship between ethnicity, physical activity, risk factors for metabolic disease and the amount of physical activity required to achieve low cardio-metabolic disease risk [25-27]. However, much of the variability in cardio-respiratory fitness appears to be due to non-genetic factors [23, 24, 28].

Lifestyle changes play a key role in preventing or delaying the development of T2DM. Results from large, clinical trials demonstrate that relatively modest changes in diet and physical activity can reduce the development of T2DM by around half $[29,30]$. Systematic review evidence suggests that 'realworld' lifestyle interventions are both effective [31,32] and cost-effective [33]. However, to maximise the effectiveness of these interventions in minority ethnic groups, the barriers and facilitators to healthy lifestyle changes need to be identified and understood, so that health disparities can ultimately be reduced.

In this narrative review, we explore knowledge and attitudes about diabetes risk, physical activity and diet and identify barriers and facilitators to healthy lifestyle changes in minority ethnic populations in the UK. This work formed part of a longer term strategy to inform the development and implementation of a social marketing campaign to be conducted in Leicester, UK.

\section{Methods}

\section{Search Strategy and Selection Criteria}

For this study, we conducted a narrative review, focusing on three key research topics in relation to barriers and facilitators to healthy lifestyle changes in minority ethnic populations in the UK: (i) knowledge and attitudes about diabetes risk; (ii) current behaviours and knowledge about physical activity and diet; and (iii) barriers and facilitators to living a healthier lifestyle. We used an emergent ('berry picking') model of information retrieval [34], starting with a general query on the key research topics and using both 'backward chaining' (moving backwards through a chain of reference lists) and 'forward chaining' (following a chain of citations in a forward direction) to identify primary research studies.

Inclusion criteria were primary studies involving adult minority ethnic groups residing in the UK. Studies restricted to children and adolescents were not included. We did not restrict to study type but focused on study designs that focused on interventions around T2DM in Black and minority ethnic communities/populations. We included studies reporting on the perspectives of participants with and without T2DM as some of the issues affecting healthy behaviour change, such as social norms and values, are likely to be equally applicable to both groups. Where the issues appeared to differ, the diabetes status of the participants was clarified.

For each article we extracted author, year of publication, setting, data collection methods and patient characteristics.

\section{Results}

We identified 34 articles or reports relevant to knowledge and attitudes about diabetes risk; current behaviours, knowledge and attitudes about physical activity and diet; and barriers and facilitators to living a healthier lifestyle [9, 35-67]. The articles retrieved are summarised in Table 1. Most of the studies used qualitative methods in the form of focus groups or interviews. Almost all described South Asian minority ethnic populations, either as a group or restricted to Indian, Pakistani or Bangladeshi communities [9, 36-55, 58-67]. Seven of these 


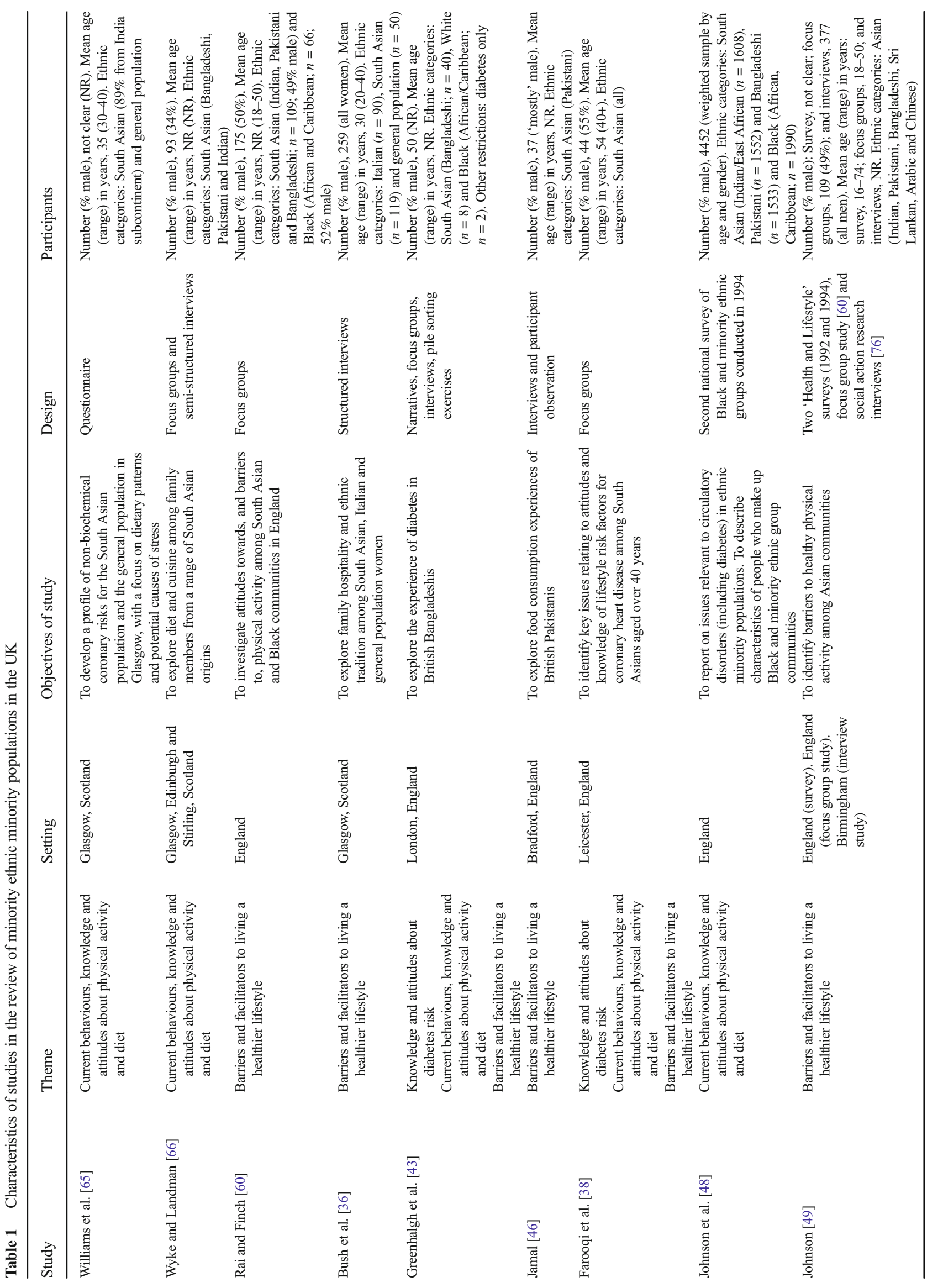




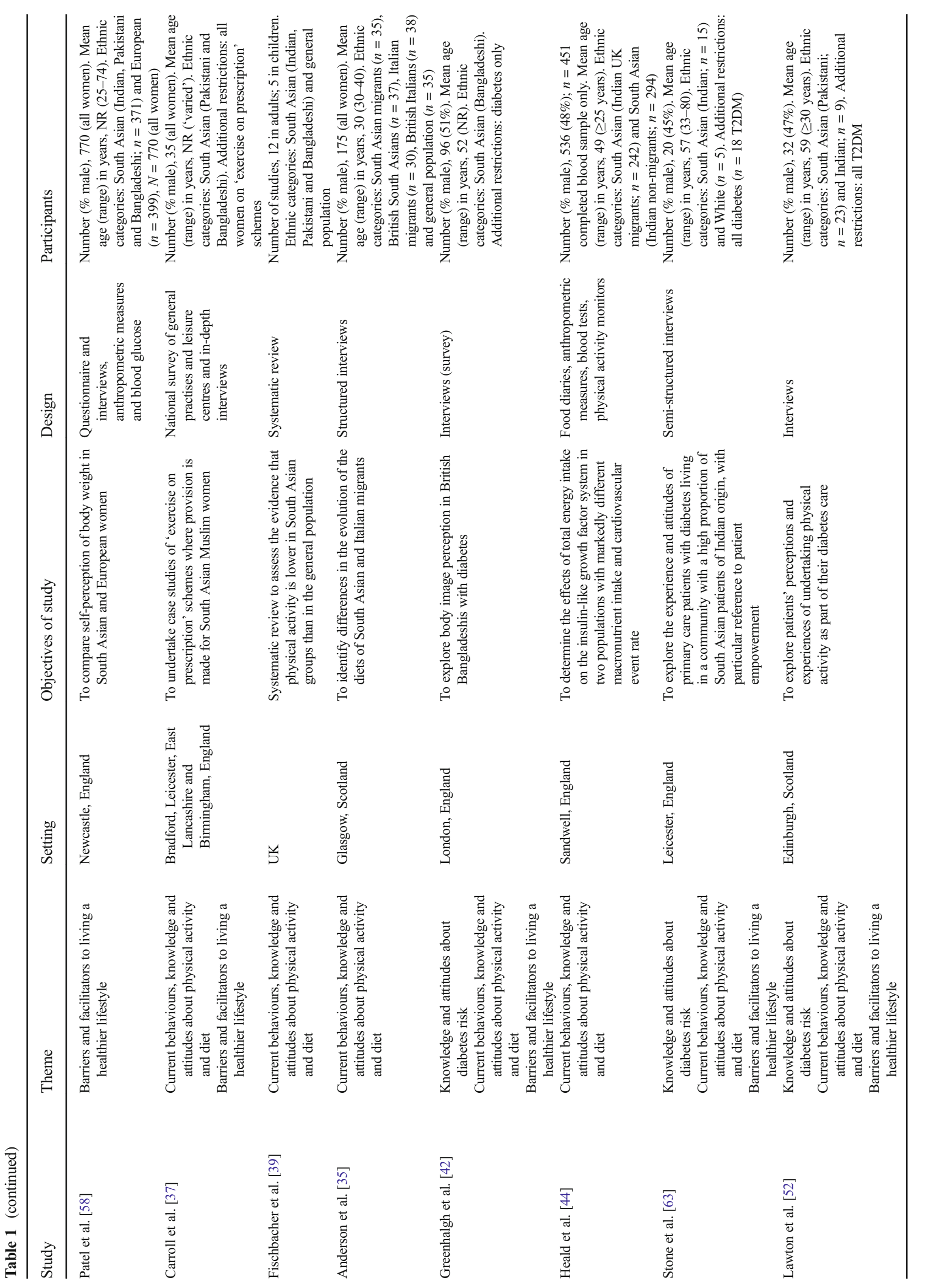




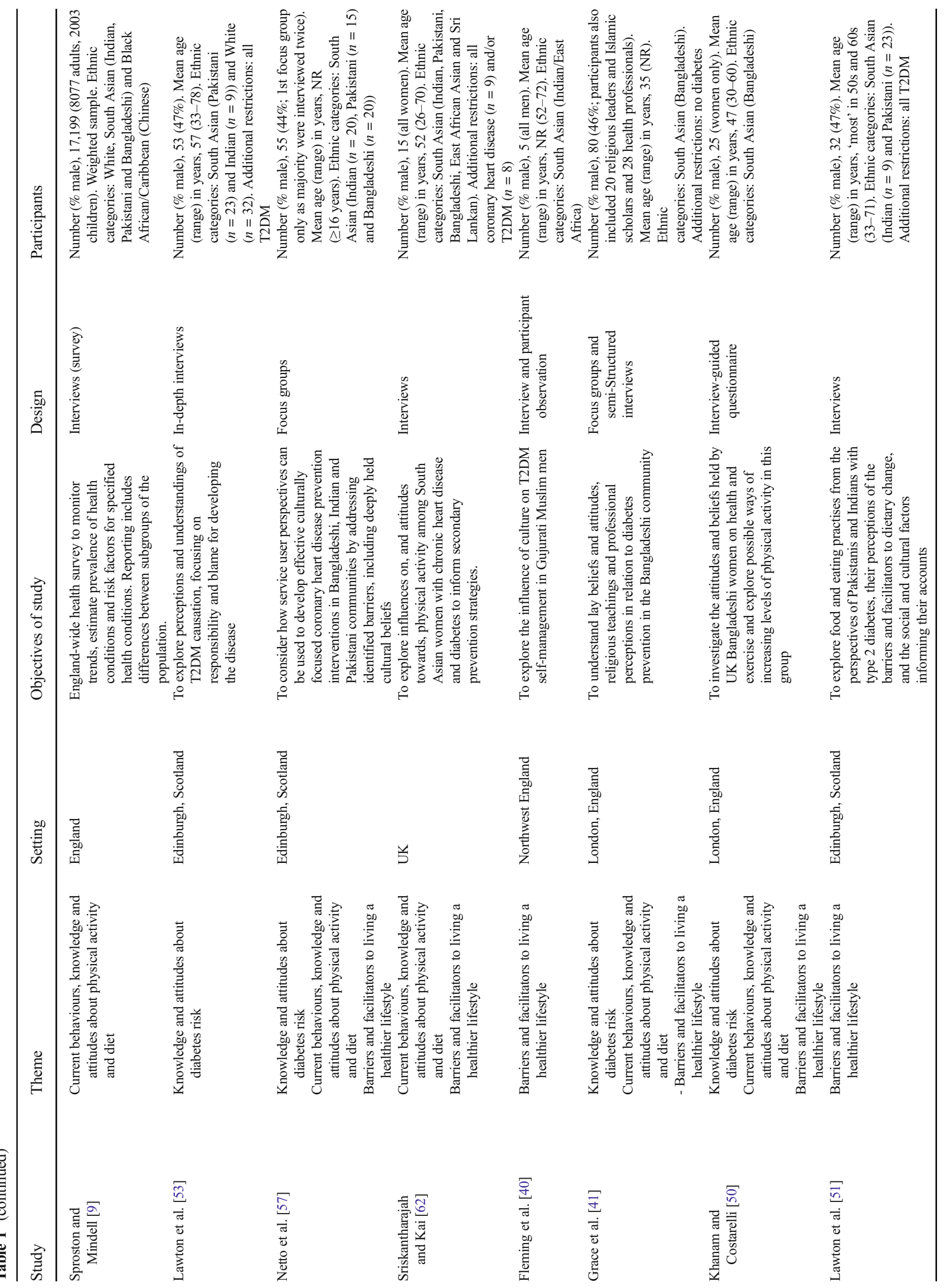




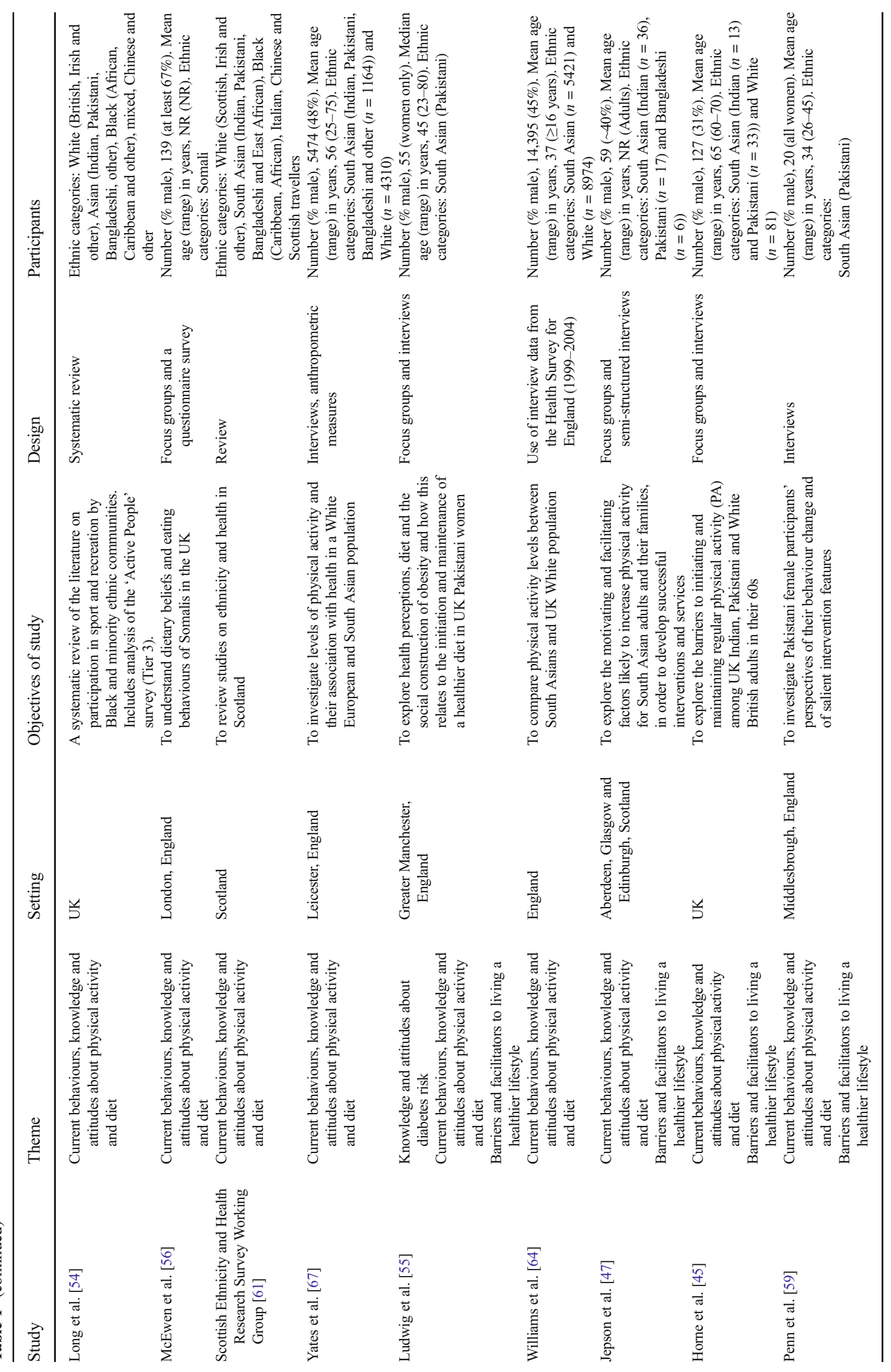


studies also included other ethnic minority populations $[9,36$, $43,48,54,60,61]$; the remaining study focused on the Somali community only [56]. Seven of the studies were restricted to people with diabetes $[42,43,51-53,62,63]$; five of these referred or restricted to people with T2DM [51-53, 62, 63]

\section{Knowledge and Attitudes About Diabetes Risk}

In total, we identified 11 studies that reported information on the knowledge and attitudes about diabetes risk among ethnic minority populations [38, 41-43, 50, 52, 53, 55, 57, 59, 63]. All of these 11 studies reported on South Asian minority ethnic populations.

In Bangladeshi [41, 42] and combined South Asian communities [57], knowledge about T2DM was reported to be high. People from Bangladeshi, Pakistani and Indian communities were also aware of their increased risk of developing T2DM $[41,59,63]$, owing partly to exposure to the condition through family members [41, 63], which could motivate lifestyle choices $[41,59]$. It was recognised that T2DM was partially preventable by avoiding certain foods, such as sugar and saturated fat $[41,42,57]$. In contrast, other studies reported that participants did not know which aspects of lifestyle behaviours or, indeed, whether obesity could contribute to the development of T2DM and cardiovascular disease [38, 50, 55].

Perceived lack of individual control in developing T2DM was prevalent among the South Asian communities studied. External causes such as genetics $[41,43,52]$ and stressful life events, often exacerbated by immigration $[38,41,50,53,55$, 57], were perceived to be important. Studies also noted fatalistic health beliefs in these communities $[41,55,57,63]$ although some attributed these to older generations [41], acknowledging that individuals were responsible for protecting their own health $[38,41]$.

\section{Current Behaviours, Knowledge and Attitudes About Physical Activity and Diet}

We identified 25 studies that reported on current behaviours, knowledge and attitudes about physical activity and diet in minority ethnic populations $[9,35,37-39,41-45,47,48$, $50,52,54-57,61-67]$. Seventeen of these reported physical activity behaviours $[9,37-39,41-43,45,47,50,52,54,55$, $57,62,64,67]$ and 11 reported dietary behaviours $[9,35,38$, $44,48,55,56,61,63,65,66]$.

The majority of the studies $(n=20)$ reported data on South Asian minority ethnic groups (Indian, Pakistani and Bangladeshi) [35, 37-39, 41-45, 47, 50, 52, 55, 57, 62-67]. Four of the studies additionally reported data on Black African, Black Caribbean and Chinese individuals [9, 48, $54,61]$. The remaining study was restricted to the British Somali population [56].

\section{Physical Activity}

A key population-based study showed differences in adherence to physical activity recommendations by minority ethnic group [9]. The survey reported results from the Health Survey for England 2004 and observed higher rates of adherence in Irish and Black Caribbean men (39\% and 37\%, respectively) and Black Caribbean, Black African and Irish women (31\%, $29 \%$ and 29\%, respectively). All South Asian groups appeared to do less physical activity than the White population. In another survey, lower levels of sports participation were observed among ethnic minority groups as a whole, compared with the White British population. However, stratification by ethnic group revealed higher participation in 'mixed' and 'Chinese and other' ethnic minority populations [54]. Similarly, systematic review evidence also suggests that South Asian minority ethnic populations, in particular South Asian women and older individuals, have lower levels of physical activity compared with White British populations [39]. More recent studies suggest that this pattern is persisting $[64,67]$.

Studies of South Asian participants showed that whilst they were generally aware of the health benefits associated with physical activity [38, 41, 47, 48, 57], they had more limited understanding of the actual levels of physical activity required to gain health benefits $[37,38,41,48,50]$. Five studies reported cultural differences in relation to perceptions of physical activity as an 'organised' activity; housework and namaz (prayer), for example, were seen as sufficient to gain health benefits [41, 43, 45, 52, 57]. Other studies also reported general resistance and lack of motivation to carrying out any organised physical activity that involved breathlessness, increased activity or sweating [41, 42, 50, 55, 57]. Information needs were also evident; South Asian women with T2DM felt that they needed more guidance from healthcare professionals on appropriate and safe levels of physical activity [62].

\section{Diet}

Two national surveys in England and Scotland collected information on dietary intake among different ethnic populations. In England, respondents from all minority ethnic groups were more likely to report meeting the fruit and vegetable intake (' 5 as day') recommendations than the White population [9]. However, in Scotland, only Chinese and AfricanCaribbean respondents were more likely to report meeting these recommendations than the White population and South Asian groups were less likely [61]. Similarly, a study in the UK Somali population suggested a lower consumption of fruit and vegetables [56].

Eating patterns in South Asian communities vary substantially by generation, household, region and country. Traditional South Asian diets that are low in meat, fish and 
dairy products and high in chapatis or rice, pulses, fruit and vegetables are also high in fibre and low in fat $[65,66]$. However, dietary transition has been observed after migration whereby consumption of convenience foods increases and vegetable consumption decreases, leading to a less healthy $\operatorname{diet}[35,44]$.

Research on African-Caribbean, Indian, Pakistani and Bangladeshi minority ethnic groups has shown that the majority had a good understanding of healthy eating messages but relatively poor understanding of foods that were high in saturated fat and fibre [48]. Among South Asians, knowledge of high saturated content and sugar of traditional South Asian food varied $[48,55,63]$. Some minority ethnic groups perceived that traditional diets were healthier than Western diets $[38,48,55]$. Somali participants made a cultural association between fruit and vegetables and poverty, and red meat with affluence, which impeded their understanding of a healthy diet [56]. Similarly, some studies indicated a lack of knowledge about how to prepare healthy food in people with and without T2DM [38, 56, 63].

\section{Barriers and Facilitators to Living a Healthier Lifestyle}

Table 2 summarises the literature on barriers and facilitators to healthy lifestyles. We identified 21 relevant studies that reported on the barriers and facilitators to living a healthier lifestyle among ethnic minority populations [36-38, 40-43, 45-47, 49-52, 55, 57-60, 62, 63]. Seven included participants with T2DM [40, 42, 51, 52, 58, 62, 63] and 14 without T2DM [36-38, 41, 43, 45-47, 49, 50, 55, 57, 59, 60].

All of the studies focused on South Asian minority ethnic groups and most reported on their perspectives as one group [36-38, 45, 47, 49, 51, 52, 57, 58, 60, 62, 63]. The remaining eight studies sought the perspectives of Bangladeshi [41-43, 50], Pakistani $[46,55,59]$ or Indian [40] communities separately. Seven of the studies explored the views of women only $[36,37,50,55,58,59,62]$.

\section{Social Norms and Values}

A common theme of the studies was the need to financially care and provide for family members and thus prioritise work over physical activity $[37,45,47,57]$. However, concern that weight gain could compromise the role of family carer or wage earner sometimes motivated physical activity [55]. Similar barriers were observed among South Asians with T2DM [52, 62].

Gender norms were also found to impede opportunities for South Asian women to engage in physical activity. There were cultural expectations to remain in the home, regardless of T2DM status $[41,50]$ and potential disapproval from other community members if seen walking or exercising outside $[37,38,52]$. Muslim women who exercised in facilities with other men anticipated disappointment from male family members [59], but there was a suggestion that 'educated' Muslim women were more empowered to resist social pressure [41].

Resistance to change was also observed with regard to cooking practises. Reducing the amount of ghee or oil was seen to render the food tasteless and could even be shameful $[38,41,55,57]$. The cultural importance of serving traditional food [57] and expectations of family members and the wider social circle also prevented dietary changes $[36,38,43,46,51$, $57,59]$. In a study of Gujarati Muslim men, family members recognised that a participant's diagnosis of T2DM necessitated changes to his diet, but not to their own [40]. Despite this, several studies found that some South Asian women were making healthier changes to their diets, such as eating smaller portions and reducing fat $[38,57,59]$.

Another barrier related to cultural pressure when visiting family members' homes or attending celebratory events. Feelings of having to live up to cultural expectations of food and eating practises to avoid being alienated continued, even after being diagnosed with T2DM [40, 52, 63].

Perceptions of body weight, body image and social acceptability of being overweight have been shown to differ between minority ethnic groups $[41,49,50,55,57]$. In one study, health professionals asserted that Bangladeshi people associated obesity with good health and fertility [41]. Conversely, another study of Bangladeshi participants with T2DM found that they were able to identify accurately if they were overweight and perceived obesity to be unattractive, unhealthy and associated with low fertility [42]. In a study comparing perceptions of weight among South Asian and White British women with T2DM, South Asian women were more likely to perceive their body weight as normal, despite being overweight [58].

\section{Structural Factors}

Several studies found cultural barriers to participation in physical activity related to mixed gender venues $[38,41,45,52$, 62] and facilities [37, 38, 52, 59] among Muslim male and female participants. Muslim women also expressed uncertainty as to the appropriateness of wearing traditional clothes to exercise or western clothes which could draw attention to their bodies [41]. In one study, British Bangladeshi participants felt that the music and images to which they were exposed in the gym conflicted with their cultural beliefs [50]. Some of these barriers could be overcome by incorporating physical activity classes in places of worship (mosques) [47].

Language barriers were also found to discourage participants from taking part in physical activity because they would be unable to ask for help [52,62] or understand instruction [50]. Some participants relied on relatives to accompany them and act as translators [37,63]. Such barriers might be expected to lessen in importance over time in the UK owing to the 


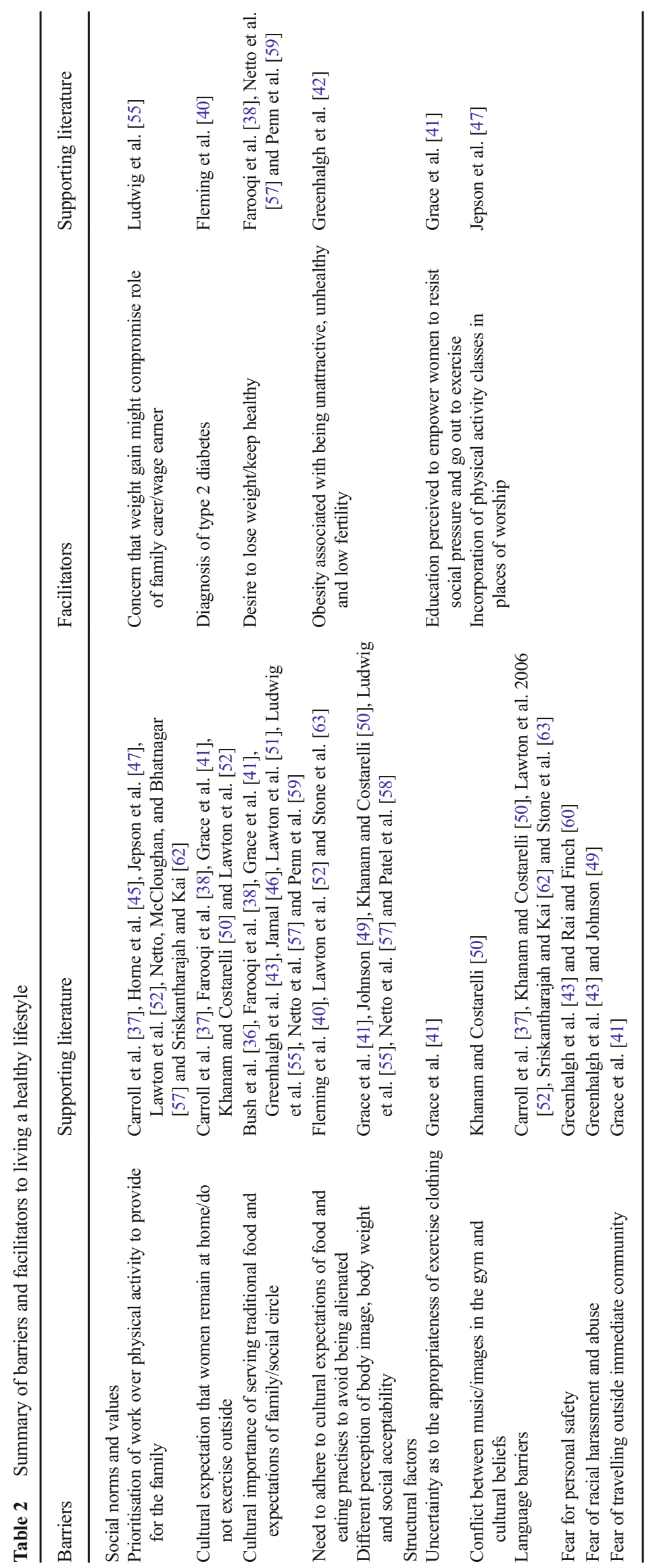


decrease in the proportion of first-generation migrants in the South Asian population.

An additional structural barrier related to concerns over personal safety $[43,60]$, racial harassment and abuse [43, 49], which deterred participants from using facilities and open spaces in the community. Additional fears were expressed in relation to travelling outside the perceived safety of the immediate community [41].

\section{Discussion}

In this narrative review, we have synthesised the literature in relation to barriers and facilitators to healthy lifestyle changes in minority ethnic populations in the UK. We have also summarised the literature on knowledge and attitudes about diabetes risk, physical activity and diet in ethnic minority populations.

The first point to note from the findings in this review is that most of the literature related to South Asian communities. This is not entirely surprising given that this population is the most widely represented ethnic minority group in the UK and that T2DM is known to be more prevalent in this population [68-70]. However, the dearth of literature on other ethnic minority populations living in the UK is a concern, and we would recommend further research in these communities.

Secondly, it is important to recognise that ethnic minority populations are not a homogeneous group, as is reflected in the diverse and often contrasting findings from the studies included in the review. Ethnicity is defined by a complex interplay of characteristics, which include spoken language, religious beliefs and common heritage, and people within and between ethnic groups vary considerably. Therefore, when making observations, it is important to consider contextual as well as cultural barriers, and caution needs to be applied in assuming our findings are transferable. Despite this, we can make some general observations from the findings to consider when developing culturally appropriate lifestyle interventions, which are particularly relevant to South Asian populations on whom most of the research was focused.

With regard to knowledge and attitudes about diabetes risk, most of the South Asian participants in our studies recognised that they were at an increased risk of developing T2DM. However, many did not attribute this increased risk to lifestyle behaviours or obesity and often perceived external events, such as genetics, stress and fatalistic beliefs, to be more important. These findings are largely supported in the USA where South Asian-Indian participants recognised their increased cardiovascular risk but were generally sceptical about the role of obesity, citing destiny or 'karma' as more likely influences [71].

We found some evidence that South Asian minority populations were less likely to engage in physical activity compared with the White population and that South Asian participants were unsure how much physical activity was needed to give health benefits. It was not clear whether or how dietary intake varied between South Asian and White populations, but there were some misunderstandings, some of them cultural, about foods that constituted a healthy diet.

In terms of barriers and facilitators to living a healthy lifestyle, family and community pressures to conform to the social norms and values in South Asian cultures were seen to be particularly important. Barriers included prioritising work over physical activity to provide for the family, the need to serve and eat traditional food and different perceptions of a healthy body weight. Similar findings have been found in South Asian Indians living in the USA [72] and Australia [73] where family responsibilities were prioritised over physical activity. Interestingly, in both of these studies, car travel was seen as a barrier to physical activity, which was not mentioned in any of the studies included in our review. Other barriers to physical activity included fear of racial harassment or abuse when exercising and, for women, expectations to remain in the home, fear for personal safety, lack of same gender venues and concerns over the acceptability of wearing 'western' exercise clothing. Facilitators included concern that weight gain might compromise family/carer responsibilities, desire to be healthy, T2DM diagnosis, and exercise classes held in 'safe' environments such as places of worship.

\section{Strengths and Weaknesses}

The purpose of this narrative review was to summarise the evidence by giving an overview of primary research published in this topic area. We did not carry out a systematic search of the literature nor include grey literature. We also did not appraise the quality of the studies. It is recognised that narrative reviews are prone to selection bias [74] and provide weak evidence for making clinical decisions about the care of individual patients [75]. However, we are able to present a broad perspective on barriers and facilitators to healthy lifestyle changes in minority ethnic, in particular South Asian, populations.

\section{Closing Remarks}

Minority ethnic populations experience a disproportionate burden of health inequalities compared with the White population, including an increased risk of T2DM. Findings from this review highlight the importance of considering social, structural and cultural contexts when engaging South Asian populations in T2DM preventive strategies. Further research of other ethnic minority populations is urgently needed to explore knowledge and attitudes about diabetes risk and lifestyle factors and to identify barriers and facilitators to healthy lifestyle changes. 


\section{Compliance with Ethical Standards}

Conflict of Interest Naina Patel declares that she has no conflict of interest. Dr. Harriet Batista Ferrer declares that she has no conflict of interest. Freya Tyrer declares that she has no conflict of interest. Paula Wray declares that she has no conflict of interest. Azhar Farooqi declares that he has no conflict of interest. Professor Melanie Davies is a member of the National Institute for Health and Clinical Excellence public health guidance on preventing type 2 diabetes and adviser to the UK Department of Health for the NHS Health Checks Programme. She has acted as consultant, advisory board member and speaker for Novo Nordisk, Sanofi-Aventis, Lilly, Merck Sharp and Dohme, Boehringer Ingelheim, AstraZeneca and Janssen and as a speaker for Mitsubishi Tanabe Pharma Corporation. She has received grants in support of investigator and investigator-initiated trials from Novo Nordisk, Sanofi-Aventis and Lilly. Professor Kamlesh Khunti (Chair) is a member of the National Institute for Health and Clinical Excellence public health guidance on preventing type 2 diabetes and adviser to the UK Department of Health for the NHS Health Checks Programme. He has acted as a consultant, served on advisory boards for and speaker for Novartis, Novo Nordisk, Sanofi-Aventis, Lilly, Janssen, Boehringer Ingelheim and Merck Sharp and Dohme. He has received grants in support of investigator and investigator-initiated trials from Novartis, Novo Nordisk, SanofiAventis, Lilly, Roche, Boehringer Ingelheim and Merck Sharp and Dohme.

Research Involving Human Participants and/or Animals This article does not contain any studies with human participants performed by any of the authors.

Informed Consent Not applicable - this article does not contain any studies with human participants performed by any of the authors.

Funding This study was funded by the National Institute for Health Research Collaboration for Leadership in Applied Health Research and Care-East Midlands (NIHR CLAHRC-EM), with support from the Leicester Clinical Trials Unit and the NIHR Leicester-Loughborough Diet, Lifestyle and Physical Activity Biomedical Research Unit, which is a partnership between University Hospitals of Leicester NHS Trust, Loughborough University and the University of Leicester. The views expressed are those of the authors and are not necessarily those of the NHS, the NIHR or the Department of Health.

Open Access This article is distributed under the terms of the Creative Commons Attribution 4.0 International License (http:// creativecommons.org/licenses/by/4.0/), which permits unrestricted use, distribution, and reproduction in any medium, provided you give appropriate credit to the original author(s) and the source, provide a link to the Creative Commons license, and indicate if changes were made.

\section{References}

1. Fischbacher CM, Bhopal R, Steiner M, Morris AD, Chalmers J. Is there equity of service delivery and intermediate outcomes in south Asians with type 2 diabetes? Analysis of DARTS database and summary of UK publications. Journal of Public Health. 2009;31(2):239-49.

2. Simmons D, Williams DR, Powell MJ. Prevalence of diabetes in a predominantly Asian community: preliminary findings of the Coventry diabetes study. Br Med J. 1989;298(6665):18.
3. Unwin N, Alberti KGMM, Bhopal R, Harland J, Watson W, White M. Comparison of the current WHO and new ADA criteria for the diagnosis of diabetes mellitus in three ethnic groups in the UK. Diabet Med. 1998;15(7):554-7.

4. Riste L, Khan F, Cruickshank K. High prevalence of type 2 diabetes in all ethnic groups, including Europeans, in a British inner city relative poverty, history, inactivity, or twenty-first century Europe? Diabetes Care. 2001;24(8):1377-83.

5. Holman N, Forouhi NG, Goyder E, Wild SH. The Association of Public Health Observatories (APHO) diabetes prevalence model: estimates of total diabetes prevalence for England, 2010-2030. Diabet Med. 2011;28(5):575-82.

6. Department of Health. Modern standards and service models - diabetes: National Service Framework Standards. London: Department of Health; 2001.

7. World Health Organisation. Preventing chronic diseases. A vital investment. WHO global report. Geneva: World Health Organisation; 2005.

8. World Health Organisation. Global action plan for the prevention and control of noncommunicable diseases 2013-2020. Geneva: WHO; 2013.

9. Sproston K, Mindell J. Health Survey for England 2004: the health of minority ethnic groups Leeds: NHS Health and Social Care Information Centre 2006.

10. Razak F, Anand SS, Shannon H, Vuksan V, Davis B, Jacobs R, et al. Defining obesity cut points in a multiethnic population. Circulation. 2007;115(16):2111-8.

11. Gray LJ, Yates T, Davies MJ, Brady E, Webb DR, Sattar N, et al. Defining obesity cut-off points for migrant South Asians. PLoS One. 2011;6(10):e26464.

12. Deurenberg P, Deurenberg-Yap M, Guricci S. Asians are different from Caucasians and from each other in their body mass index/ body fat per cent relationship. Obes Rev. 2002;3(3):141-6.

13. Rush E, Plank L, Chandu V, Laulu M, Simmons D, Swinburn B, et al. Body size, body composition, and fat distribution: a comparison of young New Zealand men of European, Pacific Island, and Asian Indian ethnicities. N Z Med J. 2004;117(1207):U1203.

14. World Health Organisation. Global strategy on diet, physical activity and health. Geneva: World Health Organisation; 2004.

15. Kumar S, Hanif W, Zaman MJ, Sattar N, Patel K, Khunti K. Lower thresholds for diagnosis and management of obesity in British South Asians. Int J Clin Pract. 2011;65(4):378-9.

16. Hirani V, Stamatakis E. Anthropometric measures, overweight, and obesity. The Scottish Health Survey. 2004;6:163-203.

17. Wen CP, David Cheng TY, Tsai SP, Chan HT, Hsu HL, Hsu CC, et al. Are Asians at greater mortality risks for being overweight than Caucasians? Redefining obesity for Asians. Public Health Nutr. 2009;12(4):497-506.

18. Food Standards Agency. Healthy diet. London: Food Standards Agency; 2010. Available from: http://www.food.gov. uk/sites/default/files/multimedia/pdfs/publication/eatwell0708.pdf.

19. Gilbert PA, Khokhar S. Changing dietary habits of ethnic groups in Europe and implications for health. Nutr Rev. 2008;66(4):203-15.

20. Physical Activity Guidelines Advisory Committee. Physical activity guidelines for Americans. Washington, DC: US Department of Health and Human Services; 2008. p. 15-34.

21. World Health Organisation. Global recommendations on physical activity for health. Geneva: World Health Organisation; 2010.

22. Department of Health. Start active, stay active: a report on physical activity from the four home countries' chief medical officers. London: Department of Health; 2011.

23. Bouchard C, An P, Rice T, Skinner JS, Wilmore JH, Gagnon J, et al. Familial aggregation of VO2max response to exercise training: results from the HERITAGE family study. J Appl Physiol. 1999;87(3):1003-8. 
24. Bouchard C, Warwick DE, Rice T, Perusse L, Gagnon J, Province $\mathrm{MA}$, et al. Familial resemblance for VO2max in the sedentary state: the HERITAGE family study. Med Sci Sports Exerc. 1998;30(2): $252-8$.

25. Abdullah A, Peeters A, De Courten M, Stoelwinder J. The magnitude of association between overweight and obesity and the risk of diabetes: a meta-analysis of prospective cohort studies. Diabetes Res Clin Pract. 2010;89(3):309-19.

26. Gill JMR, Celis-Morales CA, Ghouria N. Physical activity, ethnicity and cardio-metabolic health: does one size fit all? Atherosclerosis. 2014;232(2):319-33.

27. Celis-Morales CA, Ghouri N, Bailey MES, Sattar N, Gill JMR. Should physical activity recommendations be ethnicity-specific? Evidence from a cross-sectional study of South Asian and European men. PLoS One. 2013;8(12):e82568.

28. O'Donovan G, Bakrania K, Ghouri N, Yates T, Gray LJ, Hamer M, et al. Nonexercise equations to estimate fitness in White European and South Asian men. Med Sci Sports Exerc. 2016;48(5):854-9.

29. Diabetes Prevention Program Research Group. Reduction in the incidence of type 2 diabetes with lifestyle intervention or metformin. N Engl J Med. 2002;346(6):393.

30. Lindström J, Ilanne-Parikka P, Peltonen M, Aunola S, Eriksson JG, Hemiö K, et al. Sustained reduction in the incidence of type 2 diabetes by lifestyle intervention: follow-up of the Finnish diabetes prevention study. Lancet. 2006;368(9548):1673-9.

31. Dunkley AJ, Bodicoat DH, Greaves CJ, Russell C, Yates T, Davies MJ, et al. Diabetes prevention in the real world: effectiveness of pragmatic lifestyle interventions for the prevention of type 2 diabetes and of the impact of adherence to guideline recommendations: a systematic review and meta-analysis. Diabetes Care. 2014;37(4):922-33.

32. Gillies CL, Abrams KR, Lambert PC, Cooper NJ, Sutton AJ, Hsu RT, et al. Pharmacological and lifestyle interventions to prevent or delay type 2 diabetes in people with impaired glucose tolerance: systematic review and meta-analysis. Br Med J. 2007;334(7588): 299.

33. Gillies CL, Lambert PC, Abrams KR, Sutton AJ, Cooper NJ, Hsu RT, et al. Different strategies for screening and prevention of type 2 diabetes in adults: cost effectiveness analysis. Br Med J. 2008;336: $1180-5$.

34. Booth A. Unpacking your literature search toolbox: on search styles and tactics. Health Inf Libr J. 2008;25:313-7.

35. Anderson AS, Bush H, Lean M, Bradby H, Williams R, Lea E. Evolution of atherogenic diets in south Asian and Italian women after migration to a higher risk region. Journal of Human Nutrition \& Dietetics. 2005;18(1):33-43.

36. Bush H, Williams R, Bradby H, Anderson A, Lean M. Family hospitality and ethnic tradition among South Asian, Italian and general population women in the West of Scotland. Sociology of Health \& Illness. 1998;20(3):351-80.

37. Carroll R, Ali N, Azam N. Promoting physical activity in south Asian Muslim women through "exercise on prescription". Health Technol Assess. 2002;6:1-101.

38. Farooqi A, Nagra D, Edgar T, Khunti K. Attitudes to lifestyle risk factors for coronary heart disease amongst south Asians in Leicester: a focus group study. Fam Pract. 2000;17(4):293-7.

39. Fischbacher CM, Hunt S, Alexander L. How physically active are South Asians in the United Kingdom? A literature review. Journal of Public Health. 2004;26(3):250-8.

40. Fleming E, Carter B, Pettigrew J. The influence of culture on diabetes self-management: perspectives of Gujarati Muslim men who reside in Northwest England. J Clin Nurs. 2008;17(5a):51-9.

41. Grace C, Begum R, Subhani S, Kopelman P, Greenhalgh T. Prevention of type 2 diabetes in British Bangladeshis: qualitative study of community, religious, and professional perspectives. $\mathrm{Br}$ Med J. 2008;337:a1931.
42. Greenhalgh T, Chowdury M, Wood GW. Big is beautiful? A survey of body image perception and its relation to health in British Bangladeshis with diabetes. Psychology, Health \& Medicine. 2005;10(2):126-38

43. Greenhalgh T, Helman C, Chowdury AM. Health beliefs and folk models of diabetes in British Bangladeshis: a qualitative study. $\mathrm{Br}$ Med J. 1998;316(7136):978-83.

44. Heald AH, Sharma R, Anderson SG, Vyas A, Siddals K, Patel J, et al. Dietary intake and the insulin-like growth factor system: effects of migration in two related populations in India and Britain with markedly different dietary intake. Public Health Nutr. 2005;8(6):620-7.

45. Horne M, Skelton DA, Speed S, Todd C. Perceived barriers to initiating and maintaining physical activity among South Asian and White British adults in their 60 s living in the United Kingdom: a qualitative study. Ethnicity \& Health. 2013;18(6): 626-45. doi:10.1080/13557858.2013.814762.

46. Jamal A. Food consumption among ethnic minorities: the case of British-Pakistanis in Bradford, UK. Br Food J. 1998;100(5):221-7.

47. Jepson R, Harris FM, Bowes A, Robertson R, Avan G, Sheikh A. Physical activity in south Asians: an in-depth qualitative study to explore motivations and facilitators. PLoS One. 2012;7(10): e45333.

48. Johnson M, Owen D, Blackburn C. Black and minority ethnic groups in England: the second health and lifestyles survey. In: health education authority, editor. London: Health Education Authority; 2000.

49. Johnson MRD. Perceptions of barriers to healthy physical activity among Asian communities. Sport Educ Soc. 2000;5(1):51-70.

50. Khanam S, Costarelli V. Attitudes towards health and exercise of overweight women. J R Soc Promot Heal. 2008;128(1):26-30.

51. Lawton J, Ahmad N, Hanna L, Douglas M, Bains H, Hallowell N. 'We should change ourselves, but we can't': accounts of food and eating practices amongst British Pakistanis and Indians with type 2 diabetes. Ethnicity \& Health. 2008;13(4):305-19.

52. Lawton J, Ahmad N, Hanna L, Douglas M, Hallowell N. 'I can't do any serious exercise': barriers to physical activity amongst people of Pakistani and Indian origin with type 2 diabetes. Health Educ Res. 2006;21(1):43-54.

53. Lawton J, Ahmad N, Peel E, Hallowell N. Contextualising accounts of illness: notions of responsibility and blame in White and South Asian respondents' accounts of diabetes causation. Sociology of Health \& Illness. 2007;29(6):891-906.

54. Long J, Hylton K, Spracklen K, Ratna A, Bailey S, Hall C, et al. A systematic review of the literature on Black and minority ethnic communities in sport and physical recreation. Leeds: Carnegie Research Institute, Leeds Metropolitan University; 2009.

55. Ludwig AF, Cox P, Ellahi B. Social and cultural construction of obesity among Pakistani Muslim women in North West England. Public Health Nutr. 2011;14(10):1842-50.

56. McEwen A, Straus L, Croker H. Dietary beliefs and behaviour of a UK Somali population. J Hum Nutr Diet. 2009;22(2):116-21.

57. Netto G, McCloughan L, Bhatnagar A. Effective heart disease prevention: lessons from a qualitative study of user perspectives in Bangladeshi, Indian and Pakistani communities. Public Health. 2007;121(3):177-86.

58. Patel S, Bhopal R, Unwin N, White M, Alberti KGMM, Yallop J. Mismatch between perceived and actual overweight in diabetic and non-diabetic populations: a comparative study of south Asian and European women. JEpidemiol Community Health. 2001;55(5):332-3.

59. Penn L, Dombrowski SU, Sniehotta FF, White M. Perspectives of UK Pakistani women on their behaviour change to prevent type 2 diabetes: qualitative study using the theory domain framework. BMJ Open. 2014;4(7):e004530. 
60. Rai DK, Finch H. Physical activity 'from our point of view': qualitative research among south Asian and Black communities. London: Health Education Authority; 1997.

61. Scottish Ethnicity and Health Research Survey Working Group. Health in our multi-ethnic Scotland: future research priorities. Edinburgh: NHS Health Scotland; 2009.

62. Sriskantharajah J, Kai J. Promoting physical activity among south Asian women with coronary heart disease and diabetes: what might help? Fam Pract. 2007;24(1):71-6.

63. Stone M, Pound E, Pancholi A, Farooqi A, Khunti K. Empowering patients with diabetes: a qualitative primary care study focusing on south Asians in Leicester, UK. Fam Pract. 2005;22(6):647-52.

64. Williams ED, Stamatakis E, Chandola T, Hamer M. Assessment of physical activity levels in south Asians in the UK: findings from the health survey for England. J Epidemiol Community Health. 2011;65(6):517-21.

65. Williams R, Bhopal R, Hunt K. Coronary risk in a British Punjabi population: comparative profile of non-biochemical factors. Int $\mathrm{J}$ Epidemiol. 1994;23(1):28-37. doi:10.1093/ije/23.1.28.

66. Wyke S, Landman J. Healthy eating? Diet and cuisine amongst Scottish south Asian people. Br Food J. 1997;99(1):27-34.

67. Yates T, Davies MJ, Gray LJ, Webb D, Henson J, Gill JMR, et al. Levels of physical activity and relationship with markers of diabetes and cardiovascular disease risk in 5474 White European and South Asian adults screened for type 2 diabetes. Prev Med. 2010;51(3):290-4.

68. Shaw JE, Zimmet PZ, de Courten M, Dowse GK, Chitson P, Gareeboo $\mathrm{H}$, et al. Impaired fasting glucose or impaired glucose tolerance. What best predicts future diabetes in Mauritius? Diabetes Care. 1999;22(3):399-402.
69. Vaccaro O, Ruffa G, Imperatore G, Iovino V, Rivellese AA, Riccardi G. Risk of diabetes in the new diagnostic category of impaired fasting glucose: a prospective analysis. Diabetes Care. 1999;22(9):1490-3.

70. Gabir MM, Hanson RL, Dabelea D, Imperatore G, Roumain J, Bennett PH, et al. The 1997 American Diabetes Association and 1999 World Health Organization criteria for hyperglycemia in the diagnosis and prediction of diabetes. Diabetes Care. 2000;23(8): 1108-12.

71. Mukherjea A, Underwood KC, Stewart AL, Ivey SL, Kanaya AM. Asian Indian views on diet and health in the United States. Family \& Community Health. 2013;36(4):311-23.

72. Kalavar JM, Kolt GS, Giles LC, Driver RP. Physical activity in older Asian Indiands living in the United States: barriers and motives. Activities, Adaptation and Aging. 2004;29(1):47-67.

73. Mohan S, Wilkes L, Jackson D. Lifestyle of Asian Indians with coronary heart disease: the Australian context. Collegian. 2008;15(3):115-21.

74. La Torre G, Backhaus I, Manocci A. Rating for narrative reviews: concept and development of the international narrative systematic assessment tool. Senses and Sciences. 2015;2(1):31-5.

75. Ball C, Sackett D, Phillips B, Haynes B, Straus S. Levels of evidence and grades of recommendations. Oxford: Centre for evidence based medicine; 2009.

76. Johnson MRD, Verma C. It's our health too: Asian men's health perspectives. Coventry: University of Warwick Centre for Research in Ethnic Relations; 1998. 